\title{
How Does Economic Policy Uncertainty Connect With the Volatility Spillovers in Asia-Pacific Markets?
}

\author{
Ismail O Fasanya1, Oluwatomisin J Oyewole ${ }^{2}{ }^{a}{ }^{a}$, Taofeek Agbatogun ${ }^{3}$ \\ ${ }^{1}$ Wits Business School, University of the Witwatersrand, Johannesburg, South Africa, ${ }^{2}$ Department of Economics, Federal University of Agriculture, \\ Abeokuta, Nigeria, ${ }^{3}$ Department of Accounting, Federal University of Agriculture, Abeokuta, Nigeria \\ Keywords: asia-pacific markets, connectedness, nonlinearity, economic policy uncertainty
}

https://doi.org/10.46557/001c.21437

\section{Asian Economics Letters}

Vol. 2, Issue 2, 2021

\begin{abstract}
We examine the connection between global economic policy uncertainty (GEPU) and the dynamic spillovers of the Asia-Pacific manufacturing market within a nonparametric framework. We find strong connectedness between markets, and our results strongly support a nonlinear causal relationship between GEPU and manufacturing markets, mostly at median quantiles. Nonlinearity in our data signifies that the nonparametric test is more robust relative to the standard causality test.
\end{abstract}

\section{Introduction}

This paper examines the effect of GEPU on the connectedness between the the Asian manufacturing market. Economic policy uncertainty (EPU) refers to government policymakers' contribution to the uncertainty regarding fiscal, regulatory, or monetary policy (Hoque \& Zaidi, 2018). EPU implies that the future outlook for the economy is unpredictable. When this occurs, there is a high likelihood of adverse economic events (see also, Iyke, 2020).

Our study is relevant because GEPU is a major risk factor in global financial market performance and may negatively affect asset returns. Theoretically, spillovers in manufacturing markets can also be influenced by uncertainty through its impacts on the supply of labour, personal consumption, and investment decisions. Also, policy-induced uncertainty has diverse impacts on corporate entities, investors, and consumers as it can discourage new investments and induce conservative spending behaviours among consumers. Thus, it is not out of scope to assert that the effects of EPU on the economy can directly spillover to financial markets.

However, some industries are more sensitive to decisions driven by political events than others, implying that EPU drives long-run volatilities of specific industry-level stock markets in different ways (Yu et al., 2018). This study examines the effect of GEPU on the Asia-Pacific manufacturing market, a widely recognized world manufacturing hub. Therefore, this study is useful in providing insights for policymakers to understand their decisions' transmission mechanisms and adopt policies accordingly.

A few studies have attempted to explain the interaction between GEPU and financial markets. Yu et al. (2018) find that GEPU is positively related to financials and consumer discretionary industries' long-run volatility and negatively related to information technology, materials, telecommunication services and energy. Ersan et al. (2018) find that both European and global EPU have significant negative effects on travel and leisure companies' stock returns. Hoque \& Zaidi (2018) conclude that the Markov - switching model exhibits significant effects of GEPU on most sectoral stock returns in the case of Malaysia. However, it is still unknown to what extent GEPU affects the Asia-Pacific manufacturing market.

This paper extends the literature by examining the effect of GEPU on volatility connectedness of the Asia-Pacific manufacturing market. First, we examine volatility interactions within the market because integration indicates likely absence of potential diversification opportunities, posing exposure to risks and making the market more susceptible to greater loss in a crisis. To achieve this, we adopt the time-varying parameter vector autoregressions (TVP-VAR) approach of Antonakakis et al. (2020), which choses an optimal rolling window size and prevents loss of observations during estimation (unlike the Diebold-Yilmaz approach). Second, we investigate the causal effect of GEPU on volatility interactions within the market by utilizing the nonparametric causality-in-quantiles approach of Balcilar et al. (2018), which tests the nonlinear causality of the $k$ th order across all quantiles of the entire distribution of asset returns and is robust to the presence of misspecification errors, structural breaks, and frequent outliers, which are common in financial time series.

The rest of the paper is structured as follows. Section II describes the methodology. Section III presents the data

a Corresponding author email: oyetomisin@yahoo.com 
and empirical results, while Section IV concludes.

\section{Methodology}

The empirical analysis is divided into two parts. The first part examines the connectedness measures between the Asia-Pacific manufacturing markets using the TVP-VAR, while the second part examines the causal effects of GEPU on the market dynamics via various linear and nonlinear causality tests.

Using Antonakakis et al. (2020), we calculate the generalized impulse response functions (GIRF) and generalized forecast error variance decompositions (GFEVD), which are crucial in estimating the dynamic connectedness, as follows:

$$
\tilde{\rho}_{i j, t}(H)=\frac{\sum_{t=1}^{H-1} \alpha_{i j, t}^{2}}{\sum_{j=1}^{m} \sum_{t=1}^{H-1} \alpha_{i j, t}^{2}}
$$

with $\sum_{j=1}^{n} \tilde{\rho}_{i j, t}(H)=1$ and $\sum_{i, j=1}^{n} \tilde{\rho}_{i j, t}(H)=m$.

In Equation (1), the numerator is the cumulative effect of a shock in variable $i$, while the denominator is the cumulative effect of all shocks. Thereafter, we deduce the total connectedness index through the use of the GFEVD:

$$
\begin{aligned}
C_{t}(H) & =\frac{\sum_{i, j=1, i \neq j}^{m} \tilde{\rho}_{i j, t}(H)}{\sum_{i, j=1}^{m} \tilde{\rho}_{i j, t}(H)} * 100 \\
& =\frac{\sum_{i, j=1, i \neq j}^{m} \tilde{\rho}_{i j, t}(H)}{m} * 100
\end{aligned}
$$

In the next phase of the estimation, we follow the Balcilar et al. (2018) methodology that extends the frameworks of Nishiyama et al. (2011) and Jeong et al. (2012) by developing a test for the second moment to detect nonlinear causality. As noted by Jeong et al. (2012), the variable $x_{t}$ (GEPU) does not cause $y_{t}$ (Asia-Pacific manufacturing markets) in the $\sigma$-quantile with respect to the lag-vector of $\left\{y_{t-1}, \ldots, y_{t-q}, x_{t-1}, x_{t-q}\right\}$ if:

$$
\begin{array}{r}
Q_{\sigma}\left(y_{t} \mid y_{t-1}, \ldots, y_{t-q}, x_{t-1}, \ldots, x_{t-q}\right) \\
=Q_{\sigma}\left(y_{t} \mid y_{t-1}, \ldots, y_{t-q}\right)
\end{array}
$$

while $x_{t}$ causes $y_{t}$ in the $\sigma$ th quantile with respect to $\left\{y_{t-1}, \ldots, y_{t-q}, x_{t-1}, x_{t-q}\right\}$ if

$$
\begin{array}{r}
Q_{\sigma}\left(y_{t} \mid y_{t-1}, \ldots, y_{t-q}, x_{t-1}, x_{t-q}\right) \\
\neq Q_{\sigma}\left(y_{t} \mid y_{t-1}, \ldots, y_{t-q}\right)
\end{array}
$$

Thus, they adopt the nonparametric Granger-quantilecausality approach as suggested by Nishiyama et al. (2011). To illustrate the causality in higher-order moments, they assume:

$$
y_{t}=h\left(V_{t-1}\right)+\vartheta\left(U_{t-1}\right) \tau_{t}
$$

where $\tau_{t}$ is the white noise process, and $h(\cdot)$ and $\vartheta(\cdot)$ equal the unknown functions that satisfy pertinent conditions for stationarity. Although this specification allows non Granger-type causality testing from $U_{t-1}$ to $y_{t}$; it could detect the "predictive power" from $U_{t-1}$ to $y_{t}^{2}$ when $\vartheta(\cdot)$ is a general nonlinear function. Thus, Equation (5) is reformulated to account for the null and alternative hypothesis for causality-in-variance in Equations (6) and (7), respectively, as:

$$
\begin{aligned}
& H_{0}=P\left\{F_{y_{t}^{2} \mid W_{t-1}}\left\{Q_{\sigma}\left(y_{t} \mid W_{t-1}\right)\right\}=\sigma\right\}=1, \\
& H_{1}=P\left\{F_{y_{t}^{2} \mid W_{t-1}}\left\{Q_{\sigma}\left(y_{t} \mid W_{t-1}\right)\right\}=\sigma\right\}<1,
\end{aligned}
$$

We obtain the feasible test statistic for testing the null hypothesis in Equation (6). With the inclusion of the Jeong et al. (2012) approach, Balcilar et al. (2018) overcome the issue that causality-in-mean implies causality-in-variance. Specifically, they interpret the causality in higher-order moments through the use of the following model:

$$
y_{t}=h\left(U_{t-1}, V_{t-1}\right)+\tau_{t},
$$

Thus, the higher-order quantile causality is

$$
\begin{array}{r}
H_{0}=P\left\{F_{y_{t}^{k} \mid W_{t-1}}\left\{Q_{\sigma}\left(y_{t} \mid W_{t-1}\right)\right\}=\sigma\right\}=1, \\
\text { for } k=1,2, \ldots, k, \\
H_{1}=P\left\{F_{y_{t}^{k} \mid W_{t-1}}\left\{Q_{\sigma}\left(y_{t} \mid W_{t-1}\right)\right\}=\sigma\right\}<1, \\
\text { for } k=1,2, \ldots, k .
\end{array}
$$

Overall, we test that $x_{t}$ Granger causes $y_{t}$ in $\sigma$ th quantile up to the $k$-th moment

\section{Results \\ A. Data and preliminary analysis}

This paper employs monthly observations on the industrial sector stock indices of 10 Asia-Pacific countries: Australia, China, Hong Kong, India, Indonesia, Japan, Korea, Singapore, Taiwan, and Thailand for the period February 1997 to October 2020. Data on the industrial sector stock indices are obtained from the Thomson Reuters DataStream, and GEPU Index was developed by Baker et al. (2020) and are downloaded from http://www.policyuncertainty.com.

From Table 1, we note positive returns ${ }^{1}$ in the average values across all series except Hong Kong, which is negative (-\$0.012). High standard deviation values necessitate analyzing the volatility transmission between these markets and may indicate presence of outliers. This may not be unrelated to the recent severe impact of the COVID-19 pandemic. Furthermore, all series are positively skewed except in the case of Hong Kong, India, Japan, and Singapore, which are negatively skewed. The kurtosis statistics reveal all series are leptokurtic, and Jarque-Bera statistic confirms non-normality, suggesting the presence of nonlinearity and structural shifts along the time paths of the series such that the use of linear or constant parameter models would bring about spurious results. Hence, our choice of quantiles-based causality test. Unit root test results (presented in Panel B) also reveal all series are stationary at the $1 \%$ significance level. However, the Sollis (2009) nonlinear unit root test result appears mixed.

\section{B. Spillover results}

Table 2 presents the averaged connectedness measures. Results suggest increased connectedness between the markets as TCI value of $60.7 \%$ indicates on average, $60.7 \%$ of the forecast error variance in one country's industrial sector 
Table 1: Summary statistics for the industrial returns

\begin{tabular}{|c|c|c|c|c|c|c|c|}
\hline & \multicolumn{5}{|c|}{ Panel A: Summary Statistics } & \multicolumn{2}{|c|}{ Panel B: Unit Root Results } \\
\hline & Mean & Std. Dev. & Skewness & Kurtosis & Jarque-Bera & ADF & Sollis (2009) \\
\hline GEPU & 122.379 & 66.489 & 1.664 & 5.838 & 227.192 & $-3.7395^{c^{* *}}$ & 2.015 \\
\hline Australia & 0.172 & 5.254 & -1.011 & 6.119 & 164.131 & $-15.5582^{c^{* * *}}$ & 1.827 \\
\hline China & 0.11 & 9.783 & -0.007 & 5.622 & 81.621 & $-15.2353^{c^{* * *}}$ & $3.607^{*}$ \\
\hline Hong Kong & -0.012 & 7.738 & -0.297 & 5.62 & 85.703 & $-15.4318^{c^{* * *}}$ & $4.011^{*}$ \\
\hline India & 0.858 & 9.72 & -0.558 & 4.356 & 36.641 & $-15.1720^{c^{* * *}}$ & 2.975 \\
\hline Indonesia & 1.478 & 8.847 & 1.539 & 14.178 & 1596.143 & $-14.5621^{c^{* * *}}$ & 3.244 \\
\hline Japan & 0.238 & 6.288 & -0.628 & 4.056 & 32.001 & $-14.5949 c^{* * *}$ & 0.6 \\
\hline Korea & 0.702 & 9.711 & 0.562 & 6.27 & 141.988 & $-15.0020^{c^{* * *}}$ & 0.1301 \\
\hline Singapore & 0.205 & 6.199 & -0.228 & 4.774 & 39.861 & $-14.7782^{c^{* * *}}$ & 1.22 \\
\hline Taiwan & 0.272 & 8.853 & 0.08 & 4.338 & 21.57 & $-14.9315^{c^{* * *}}$ & 2.42 \\
\hline Thailand & 0.797 & 10.608 & 0.069 & 6.605 & 154.534 & $-16.68977^{* * *}$ & $9.763^{* * *}$ \\
\hline
\end{tabular}

This table shows the summary statistics for the industrial returns. Panel A presents descriptive statistics of the variables, while Panel B presents results of the augmented DickeyFuller (ADF) and Sollis (2009) tests. "c" is the model with constant and deterministic trend as exogenous lags are selected based on Schwarz info criteria. Finally, ******** imply that the series is stationary at $1 \%, 5 \%$ and $10 \%$ respectively.

can be attributed to the innovations in all others. Second, we obtain the net directional spillover by subtracting the total contributions received by a country FROM others from the total contributions it gives TO others. Positive (negative) values indicate the asset in question as a net shock giver (receiver).

Our results reveal a strong spillover effect across markets, with all of them significantly giving and receiving shocks. On average, Korea and Singapore are the highest net givers of shocks with values being $27.3 \%$ and $22.3 \%$, respectively, while Australia (-29.2\%) and Japan (-14\%) are the highest net shock receivers, implying they receive more than they transmit. These results strongly align with expectations and corroborate the descriptive results in Table 1, where we see Australia and Japan having positive returns.

\section{Causality results}

We proceed to examine the role of GEPU on the connectedness between these markets by investigating the causal effect of GEPU on total and net spillover for each country from a linear perspective. Results (see Table 3) reveal that GEPU's effect is significant in less than half of the cases at the $10 \%$ significance level. This may likely be attributed to the presence of nonlinearity in the series. In addition, we conduct the Broock et al. (1996) BDS test ${ }^{2}$, which establishes nonlinearity in the series. Therefore, reliance on the linear Granger-causality test may lead to spurious conclusions as it could have suffered from misspecification errors.

Given the strong evidence of nonlinearity, we turn to the results of the quantiles-based causality tests. Figure 1 summarizes the result of the causality-in-quantiles test con- ducted for both conditional-mean and variance. Overall, we find strong evidence supporting the rejection of the null hypothesis of no Granger-causality. The causal evidence is mostly significant at the middle quantiles, implying that global EPUs tend to be a strong predictor for the volatilities in the Asia-Pacific manufacturing market, especially when the market performs normally. The market may be influenced by uncertainty through its impacts on the supply of labour, personal consumption, and investment decisions as it can discourage new investments and induce conservative spending behaviour among consumers. However, the causality becomes weak at the extreme quantiles, suggesting that the effect of EPU on the connectedness within the market is sensitive to the degree of the markets' performance. When the markets are performing at their peak, economic policy seems to be weak in affecting their interactions.

\section{Conclusion}

We examine volatility transmissions between the AsiaPacific manufacturing market and investigate the causal effect of GEPU on this relationship. We find strong connectedness between the markets, and our results strongly support a nonlinear causal relationship between GEPU and the manufacturing market, mostly at median quantiles. This reflects the disturbing effects of EPU, which matters to the formulations of policies that aim to achieve stability. Our conclusion complements the emerging literature on the vulnerability of the manufacturing markets to global policy uncertainties. 
Table 2: Dynamic connectedness results

\begin{tabular}{|c|c|c|c|c|c|c|c|c|c|c|c|}
\hline & Australia & China & Hong Kong & India & Indonesia & Japan & Korea & Singapore & Taiwan & Thailand & From \\
\hline Australia & 39.700 & 4.000 & 9.000 & 8.600 & 8.100 & 14.100 & 2.600 & 9.400 & 1.700 & 2.800 & 60.300 \\
\hline China & 2.000 & 68.500 & 2.900 & 3.300 & 1.600 & 2.600 & 2.600 & 8.000 & 6.000 & 2.500 & 31.500 \\
\hline India & 5.300 & 4.300 & 5.600 & 37.800 & 2.200 & 6.700 & 12.500 & 12.100 & 3.700 & 10.000 & 62.200 \\
\hline Indonesia & 4.600 & 3.500 & 6.200 & 1.800 & 56.800 & 1.000 & 7.900 & 4.700 & 8.500 & 5.100 & 43.200 \\
\hline Japan & 9.000 & 6.200 & 7.900 & 7.700 & 2.200 & 44.700 & 3.400 & 12.700 & 3.200 & 3.000 & 55.300 \\
\hline Singapore & 3.900 & 3.800 & 14.000 & 8.700 & 3.500 & 6.200 & 12.800 & 23.300 & 11.100 & 12.500 & 76.700 \\
\hline Taiwan & 1.200 & 5.000 & 5.000 & 5.500 & 3.900 & 1.100 & 19.200 & 12.200 & 32.900 & 14.100 & 67.100 \\
\hline Thailand & 0.700 & 1.000 & 8.800 & 6.200 & 2.700 & 2.000 & 25.200 & 11.300 & 12.300 & 29.800 & 70.200 \\
\hline Contribution to others & 31.100 & 31.000 & 65.000 & 52.900 & 32.500 & 41.200 & 96.800 & 99.000 & 68.400 & 89.400 & 607.200 \\
\hline Net directional connectedness & -29.200 & -0.500 & -6.400 & -9.300 & -10.800 & -14.000 & 27.300 & 22.300 & 1.300 & 19.200 & $\mathrm{TCl}=60.7 \%$ \\
\hline
\end{tabular}

This table shows the dynamics connectedness results. TCI denotes dynmic total connectedness index. 
Table 3: Causality test results

\begin{tabular}{lcc}
\hline GEPU does not cause: & F-statistic & $P$-value \\
\hline Total Spillover & $2.771^{* *}$ & 0.064 \\
Net Australia & $5.004^{* * *}$ & 0.007 \\
Net China & 1.362 & 0.258 \\
Net Hong Kong & 0.992 & 0.372 \\
Net India & $8.265^{* * *}$ & 0.000 \\
Net Indonesia & $7.950^{* * *}$ & 0.000 \\
Net Japan & 1.203 & 0.302 \\
Net Korea & 0.567 & 0.568 \\
Net Singapore & $4.465^{* *}$ & 0.012 \\
Net Taiwan & 1.524 & 0.220 \\
Net Thailand & 0.114 & 0.893 \\
\hline
\end{tabular}

This table shows the causality test results. **** and ${ }^{* * *}$ represent a rejection of the underlying null hypothesis that GEPU does not Granger-cause each variable considered at the $1 \%$ and $5 \%$ levels of significance, respectively.
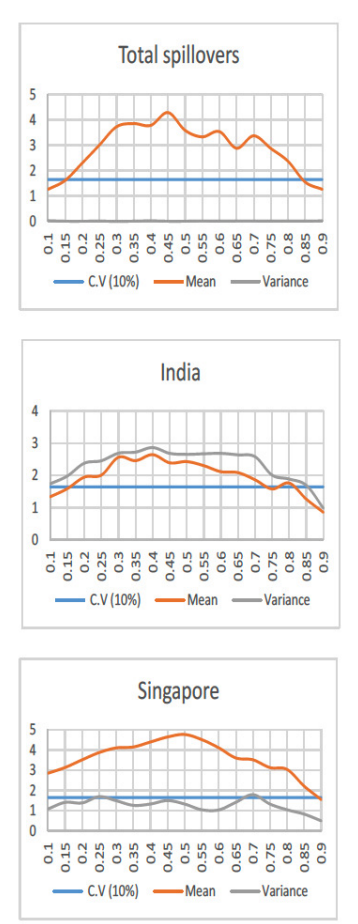
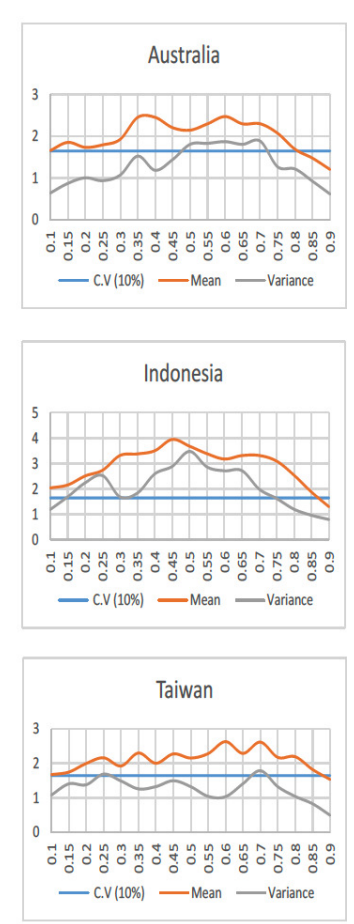
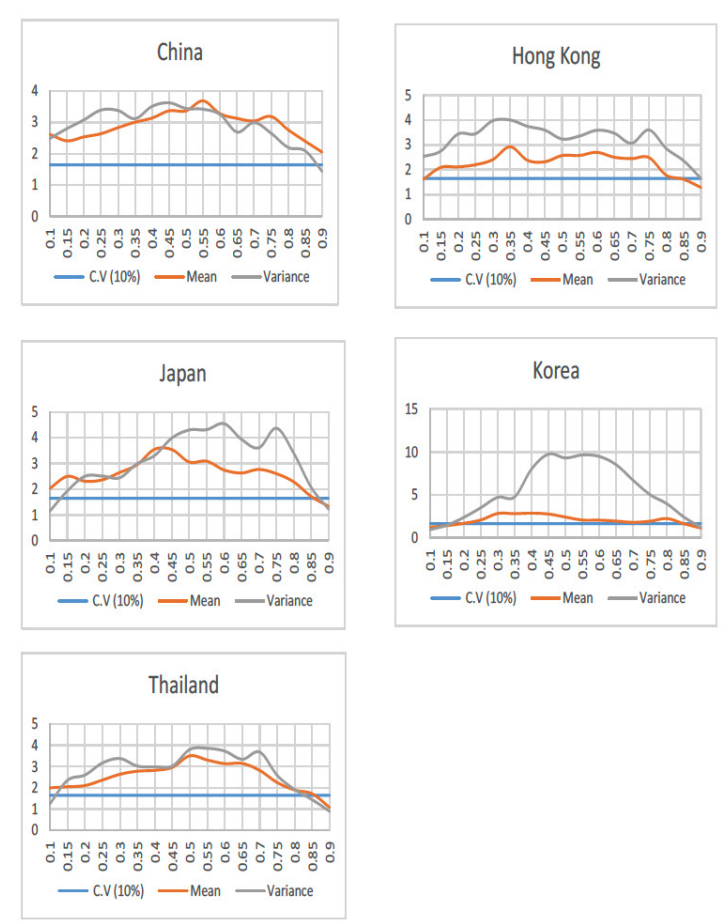

Figure 1: Quantile-based (nonlinear) causality tests in conditional mean and variance

This figure shows the quantile-based (nonlinear) causality tests in conditional mean and variance. CV represents critical value at the $10 \%$ level. 


\section{REFERENCES}

Antonakakis, N., Chatziantoniou, I., \& Gabauer, D. (2020). Redefined measures of dynamic connectedness based on time-varying parameter vector autoregressions. Journal of Risk and Financial Management, 13(4), 84. https://doi.org/10.3390/jrfm1 $\underline{3040084}$

Baker, S. R., Bloom, N., Davis, S. J., \& Terry, S. J. (2020). COVID-Induced Economic Uncertainty. National Bureau of Economic Research, Working Paper, 26983.

Balcilar, M., Gupta, R., Pierdzioch, C., \& Wohar, M. E. (2018). Terror attacks and stock-market fluctuations: Evidence based on a nonparametric causality-inquantiles test for the G7 countries. The European Journal of Finance, 24(4), 333-346. https://doi.org/1 $\underline{0.1080 / 1351847 x .2016 .1239586}$

Broock, W. A., Scheinkman, J. A., Dechert, W. D., \& LeBaron, B. (1996). A test for independence based on the correlation dimension. Econometric Reviews, 15(3), 197-235. https://doi.org/10.1080/0747493960880035 $\underline{3}$

Ersan, O., Akron, S., \& Demir, E. (2018). The effect of European global uncertainty on stock returns of travel and leisure companies. Tourism Economics, 20(10), 1-16.
Hoque, M. E., \& Zaidi, M. A. (2018). The impacts of global economic policy uncertainty on stock market returns in regime switching environment: Evidence from sectoral perspectives. International Journal Financial Economics, 5(1), 1-26.

Iyke, B. N. (2020). Economic Policy Uncertainty in Times of COVID-19 Pandemic. Asian Economics Letters, 1(2). https://doi.org/10.46557/001c.17665

Jeong, K., Härdle, W. K., \& Song, S. (2012). A consistent nonparametric test for causality in quantile. Econometric Theory, 28(4), 861-887. http s://doi.org/10.1017/s0266466611000685

Nishiyama, Y., Hitomi, K., Kawasaki, Y., \& Jeong, K. (2011). A consistent nonparametric Test for nonlinear causality-specification in time series regression. Journal of Econometrics, 165(1), 112-127. https://doi.o $\mathrm{rg} / 10.1016 / \mathrm{j}$.jeconom.2011.05.010

Sollis, R. (2009). A simple unit root test against asymmetric STAR nonlinearity with an application to real exchange rates in Nordic countries. Economic Modelling, 26(1), 118-125. https://doi.org/10.1016/j.e conmod.2008.06.002

Yu, H., Fang, L., \& Sun, B. (2018). The role of global economic policy uncertainty in long-run volatilities and correlations of US industry-level stock returns and crude oil. PLoS ONE, 13(2), e0192305. https://do i.org/10.1371/journal.pone.01 